\title{
Effect of diuretics on the plasma lipid profile
}

\author{
P. Weidmann, M. De Courten and P. Ferrari
}

Medizinische Poliklinik, University of Berne, Switzerland

KEY WORDS: Hypertension, diuretics, dyslipidaemia, glucose intolerance.

Hypertension, dyslipidaemia, glucose intolerance (associated with insulin resistance and compensatory hyperinsulinaemia) and other abnormalities are complementary coronary risk factors which often occur in association. A familial trait for essential hypertension seems to coexist commonly with defects in carbohydrate and lipoprotein metabolism which can be detected before the appearance of hypertension. Diabetes mellitus as well as obesity promotes the development of hypertension and dyslipidaemia. Moreover, certain drugs used for antihypertensive therapy can further modify lipoprotein and glucose metabolism.

Thiazides in high dosage and loop-diuretics can increase serum low-density-lipoprotein cholesterol ( $L D L-C)$ and/or very-LDL-C and the total C/high-density lipoprotein cholesterol ( $H D L-C)$ ratio, while $H D L-C$ is largely unchanged; triglycerides ( $\mathrm{Tg}$ ) are also often elevated. Premenopausal women may be protected from this side effect. Whether diureticinduced dyslipidaemia is dose-dependent and low thiazide doses (i.e. hydrochlorothiazide $\leqslant 12.5 \mathrm{mg}$ daily) are less active, awaits clarification. The diuretic-antihypertensive agent, indapamide, given at a dose of $2.5 \mathrm{mg}$. day ${ }^{-1}$, seems to exert no relevant effect on serum lipoprotein or glucose metabolism. The potassium-sparing diuretic, spironolactone, also may be largely neutral with regard to lipids. Moreover, potassium sparing diuretics may possibly counteract, at least in part, a dyslipidaemic influence of potassium-loosing diuretics in medium dose.

Drug-induced dyslipidaemia, as well as glucose intolerance, represent potentially adverse influences. In the hypertensive population, effective blood pressure control with traditional drug therapy based on thiazide-type diuretics in high dosage led to a distinct decrease in cerebrovascular morbidity and mortality, but a lesser decrease in coronary events. The prognostic relevance of drug-induced metabolic changes such as dyslipidaemia, altered insulin sensitivity, and glucose intolerance awaits further clarification. It is of clinical interest that several of the generally available antihypertensive drugs seem to be metabolically 'neutral' or sometimes perhaps even potentially beneficial with regard to the lipoprotein and glucose metabolism.

\section{Introduction}

In the hypertensive population, high-dose diuretic therapy, with the older sympatholytics or the newer $\beta$-blockers as step two agents, and hydralazine-type vasodilators as step three agents, have lowered blood pressure effectively. Such therapy also improves overall cardiovascular and, in particular, cerebrovascular prognosis, but has had less benefit on the course of coronary heart disease and the incidence of sudden death ${ }^{[l-4]}$. In patients with mild hypertension, a diuretic monotherapy in high dosage reduced stroke but not the coronary complications, whereas monotherapy with the $\beta$-blocker propranolol slightly improved both the cerebrovascular and coronary prognosis in non-smokers, but failed to provide such benefit to smokers $^{[s]}$. Suspicion has been growing that conventional antihypertensive therapy may unfavourably influence coronary risk factor(s) other than high blood pressure. Interactions with cardiac hypertrophy, electrolytes, carbohydrate and lipoprotein metabolism, angiotensin II, catecholamines, endothelial function and clotting factors are under particular consideration.

A decrease in high-density lipoprotein cholesterol (HDL-C) or increase in low density lipoprotein cholesterol (LDL-C) both augment the risk for coronary heart This work was supported by the Swiss National Science Foundation.

Correspondence: Prof P. Weidmann, Medizinische Universitåts-Poliklınik, Freiburgstrasse 3, CH-3010 Bern, Switzerland. disease $\mathrm{e}^{[6]}$. A similar tendency is suspected for elevated blood levels of triglyceride ( $\mathrm{Tg}$ )-rich lipoproteins, particularly when hypertriglyceridaemia is combined with a high LDL-C/HDL-C ratio ${ }^{77,8]}$. In recent years it has become evident that several of the drugs used for standard antihypertensive therapy may interact with the lipoprotein metabolism ${ }^{[9-12]}$.

\section{Effects of diuretics}

Thiazide-type diuretics, administered as a monotherapeutic regimen ${ }^{[2-11,13-30]}$, tend to increase serum total cholesterol (C) (reported average $+4 \%$ ), serum LDL-C (reported average $+10 \%$ ) (Fig. 1) as well as very low density lipoprotein cholesterol (VLDL-C). HDL-C (Fig. 1) and its major apoproteins $A_{1}$ and $A_{2}$ are on average unchanged. Thus, the LDL/HDL-C and total C/HDL-C ratios are frequently elevated. Loop diuretics, such as frusemide, mefruside, piretanide and muzolimine also tend to increase these ratios ${ }^{[9-11]}$. Moreover, slight increases in VLDL-triglycerides (VLDL-Tg) and/or total $\mathrm{Tg}$ (on average $+9 \%$ ) were noted in most, although not all studies with thiazide-type or loop-diuretics.

A critical aspect of any metabolic side effect is its course over time. Diuretic-induced dyslipidaemia persists for at least 1 year, with some studies documenting this alteration up to 6 years (Fig. 1). In the Multiple Risk Factor 


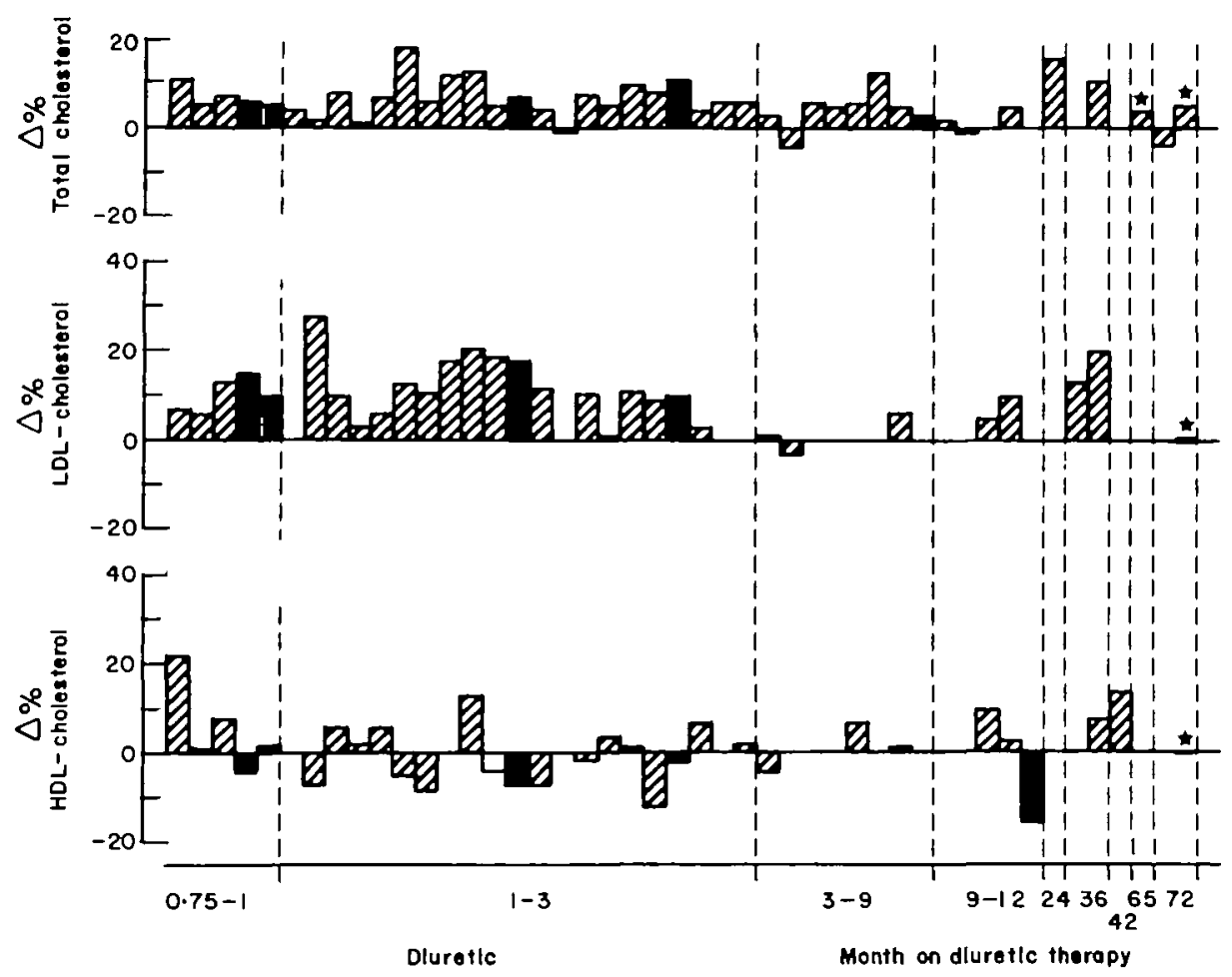

Figure I Percentage changes in serum total cholesterol, LDL-C and HDL-C in relation to the duration of a therapy with thiazide-type (hatched bars) or certain loop diuretics (closed bars); $n \geq 10$ subjects per study. Asterisks denote differences between study groups on diuretics as compared with study groups on no diuretics or no antihypertensive drugs, $\sec ^{[2]]}$ and ${ }^{[2]}$. (Reproduced with permission ${ }^{[30]}$ ).

Intervention Trial (MRFIT) ${ }^{[23]}$ and the Hypertension Detection and Follow-up Program (HDFP) ${ }^{[26]}$, a reduction in total cholesterol occurring in groups receiving no diuretics or any antihypertensive treatment, respectively, was blunted in groups receiving thiazidetype diuretics, even after 5 to 6 years of such monotherapy (Figs 2 and 3). In a further long-term study, cessation of hydrochlorothiazide (average dose $51 \mathrm{mg}$. day ${ }^{-1}$ ) after a mean treatment duration of $5 \cdot 2$ years in 23 hypertensive patients resulted in a $7 \%$ decrease in total cholesterol and a $12 \%$ reduction in LDL-C ${ }^{[3]]}$ (Fig. 4).

Gender and the menopausal state may play a role in the interaction between diuretics and lipoproteins. In postmenopausal women, chlorthalidone administered in high dosage produced changes in serum total cholesterol and LDL-C similar to those in men; no changes were seen in premenopausal women ${ }^{[32]}$ (Fig. 5). This points to a 'protective' influence of the premenopausal state. It seems that oestrogens increase the number of hepatic LDLbinding sites and stimulate the hepatic uptake of chylomicron-remnants ${ }^{[33]}$.

The development of dyslipidaemia may also be linked to the type and dose of the administered diuretics. The potassium-sparing diuretic, spironolactone, may be largely neutral with regard to plasma lipid levels ${ }^{[34-42]}$ (Fig. 6), although reported data on LDL.C are scarse and those on HDL-C also too limited to allow a firm conclusion. Effects of a monotherapy with triamterene or amiloride on the plasma lipid profile are largely unknown, one report describing a mild decrease in total $\mathrm{C}(-10 \%)$ after 7 weeks of amiloride treatment in 13 hypertensive men ${ }^{[43]}$.

Combinations of a potassium-loosing diuretic (almost always a thiazide in medium dosage, for instance hydrochlorothiazide $25-50 \mathrm{mg}$. day ${ }^{-1}$ ) with a potassiumsparing diuretic may be less prone to alter the lipoprotein metabolism than high-dose thiazides or loop-diuretics. A comprehensive analysis of reported studies reveals only minimal changes in serum total cholesterol and minor changes in total $\mathrm{Tg}$ on such combinations including either spironolactone $\left(25-50 \mathrm{mg}\right.$. day $\left.^{-1}\right)$, triamterene (approximately $20-100 \mathrm{mg} \cdot \mathrm{day}^{-1}$ ) or amiloride (2$\left.10 \mathrm{mg} \cdot \mathrm{day}^{-1}\right)^{[11,44-58]}$ (Fig. 7). As far as we know from reports, HDL-C tended to parallel total cholesterol $^{[11,48,50,51,55,58]}$. Nevertheless, interpretation is somewhat limited due to incomplete information on gender and/or the menopausal state in some reports.

The diuretic-antihypertensive agent, indapamide, in the usual antihypertensive dose of $2.5 \mathrm{mg}^{\text {. day }}{ }^{-1}$, does not produce dyslipidaemia ${ }^{[10,59]}$. (The methyl-substituted isoindoline part of indapamide differentiates this agent structurally from chlorthalidone, hydrochlorothiazide, furosemide and ticrynafen.) Compared with the rather low effective antihypertensive dose of indapamide, unnecessarily high daily doses of chlorthalidone, hydrochlorothiazide (50 to $100 \mathrm{mg}$. day ${ }^{-1}$ ) or other thiazides were generally utilized in studies focussing on interactions with lipoproteins as well as in the large therapeutic programmes in hypertensive patients. 

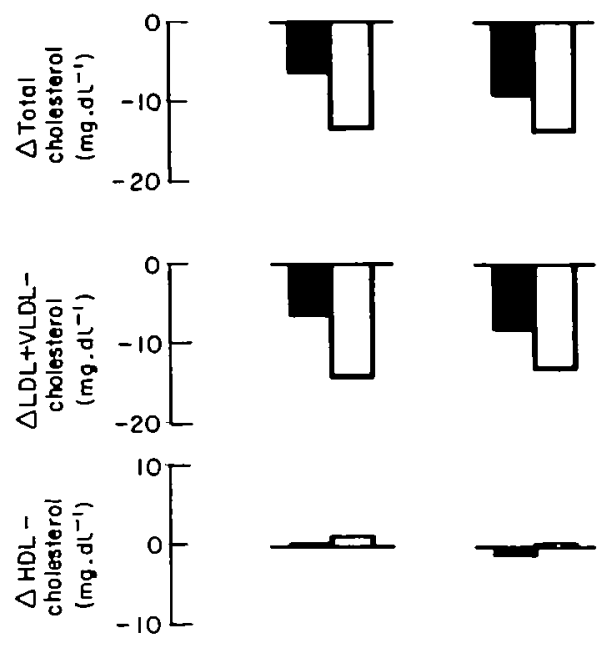

-

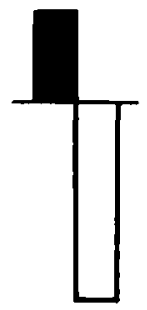

24 months

72 months

Figure 2 Absolute changes from baseline in serum total cholesterol, sum of LDL-C and VLDL-C and HDL-C (top) and in total triglycerides (bottom) in men in the MRFIT after 24 and 72 months of followup. All patients were on diet. Open bars represent patients without diuretics; closed bars, patients with diuretic therapy. (Data based on $^{(2)}$ ).

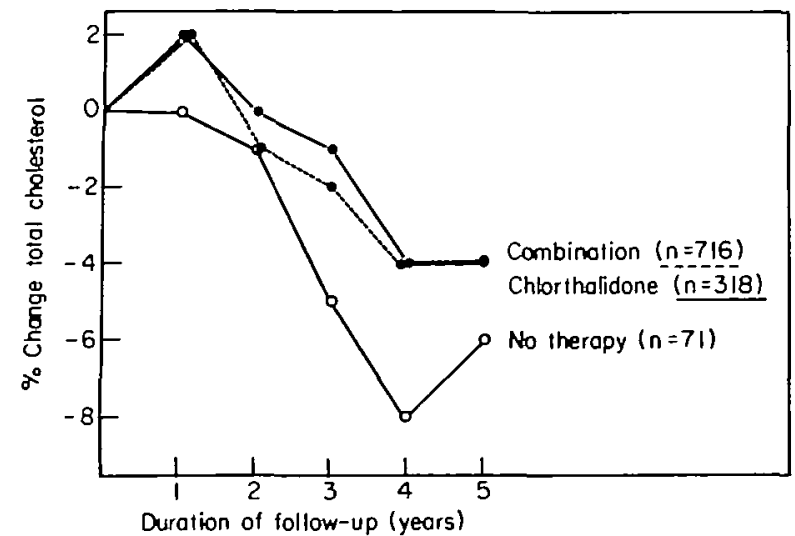

Figure 3 Percentage changes from baseline in serum total cholesterol of stepped care cohorts of patients on chlorthalidone therapy, combination therapy or no therapy, during a follow-up of 5 years in the Hypertension Detection and Follow-up Program. (Data based on $^{(2 \times)}$ ).
Hydrochtorothiazide $(n=23)$

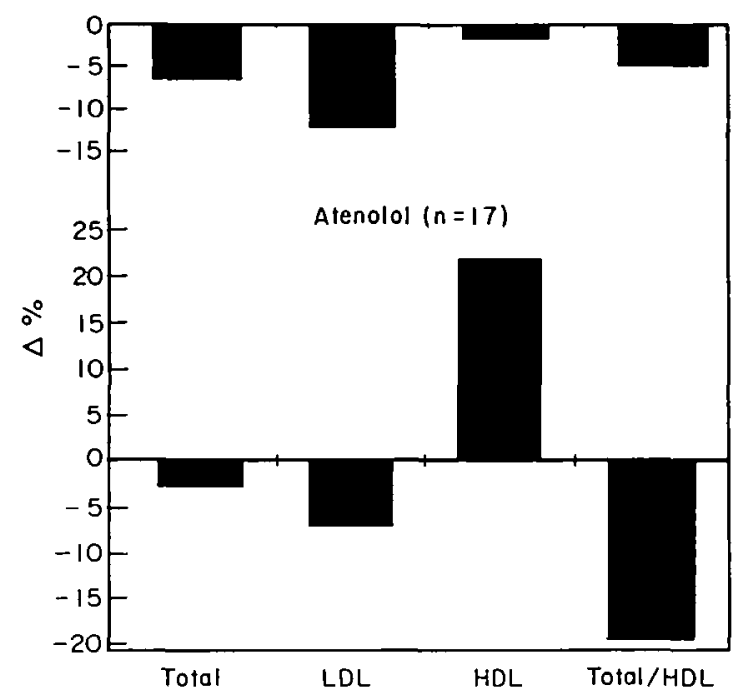

Figure 4 Percentage changes in serum cholesterol fractions 4.6 weeks after cessation of long-term antihypertensive treatment (mean duration 5.2 years) with the diuretic hydrochlorothiazide (average dose $51 \mathrm{mg}$. day ${ }^{-1} ; \mathrm{n}=23$ ) or the $\beta$-blocker atenolol (average dose $75 \mathrm{mg}$. day ${ }^{-1} ; n=17$ ). Changes in total triglycerides were $+4 \%$ or $-14 \%$ after discontinuation of hydrochlorothiazide or atenolol, respectively. (Data based on ${ }^{(31)}$ ).
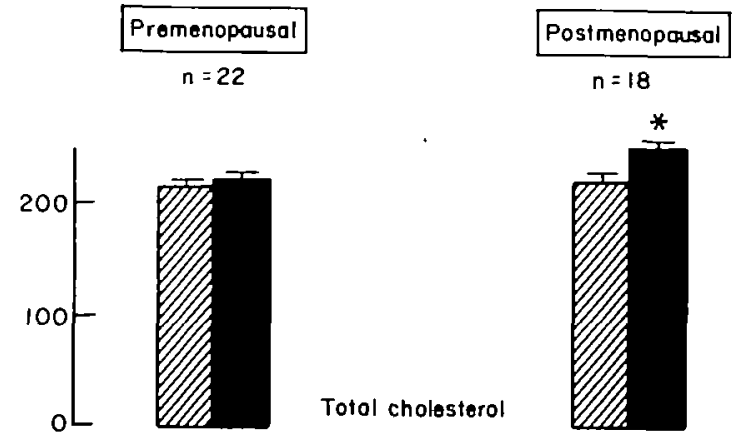

Totol cholesterol
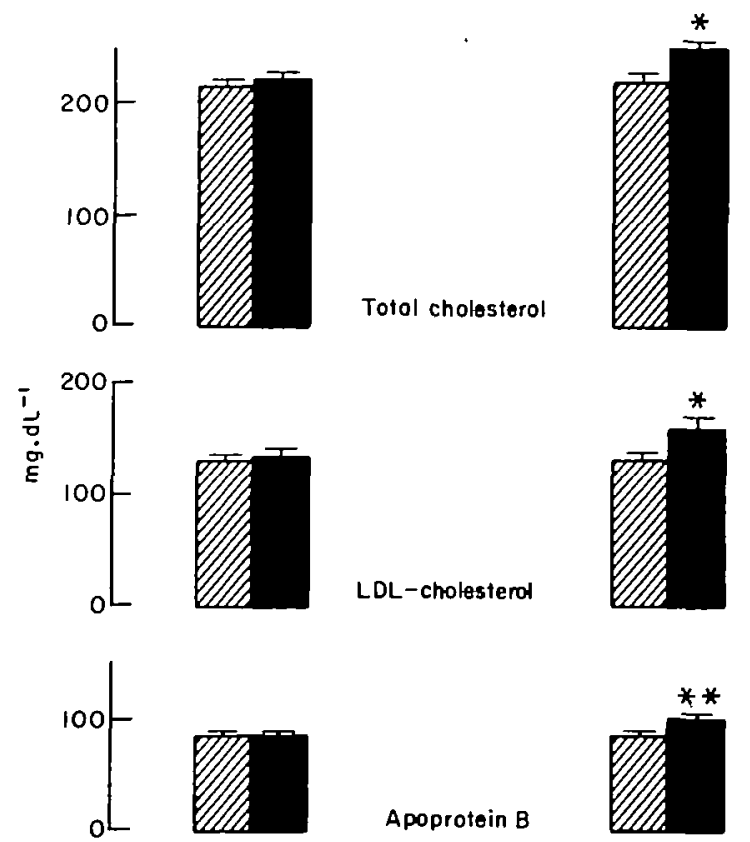

Apoprotein B

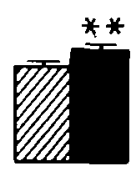

Figure 5 Effect of treatment with chlorthalidone in high dosage $\left(100 \mathrm{mg}\right.$. day ${ }^{1} \times 6$ weeks) on serum total cholesterol, LDL-cholesterol and apoprotein B in pre- or postmenopausal women. Mean values \pm SEM are shown. The $P$ values denote statistically significant differences between placebo $(Z)$ and chlorthalidone treatment $(\square)$; $*=P<0.001 ;{ }^{* *} P=0.05$. (Data based on ${ }^{(3)}$ ). 

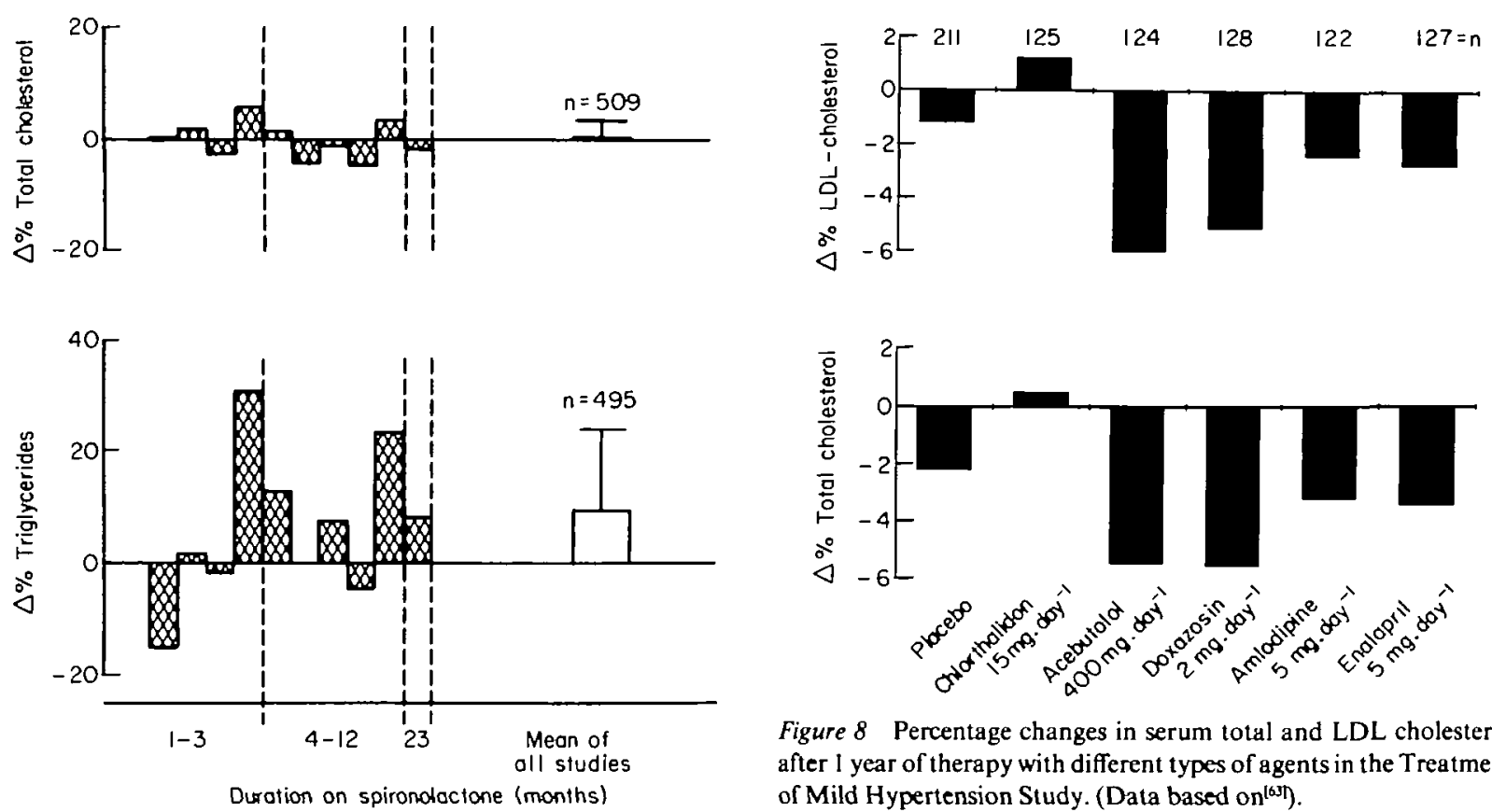

Figure 8 Percentage changes in serum total and LDL cholesterol after 1 year of therapy with different types of agents in the Treatment of Mild Hypertension Study. (Data based on ${ }^{(6)}$ ).

Figure 6 Percentage changes in serum total cholesterol and triglycerides in relation to the duration of a monotherapy with spironolactone. $n \geq 13$ subjects per study.

Average changes in all reported subjects are given as mean \pm SD.
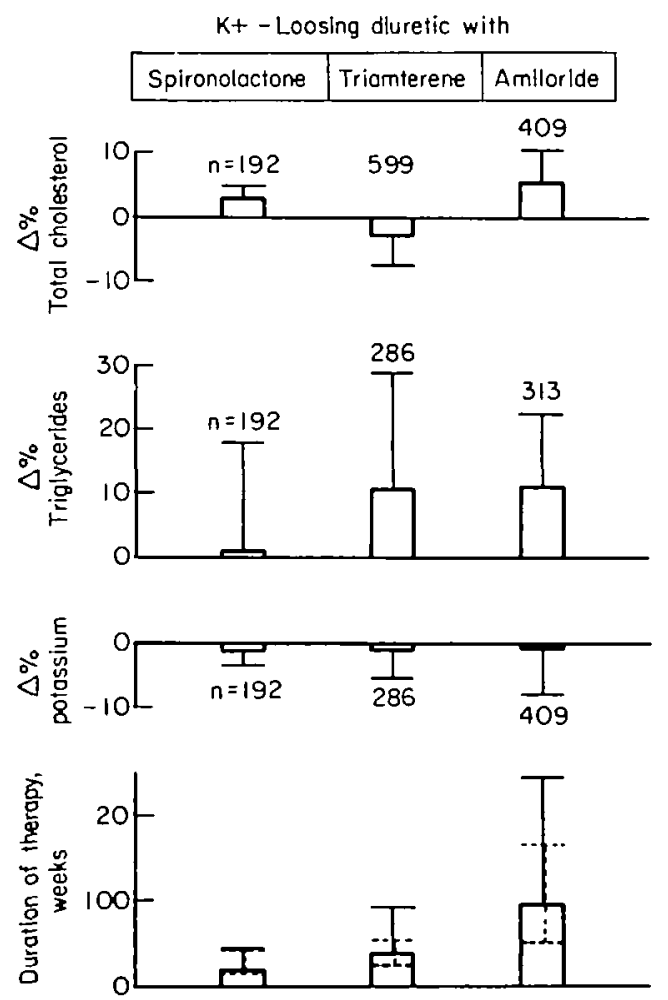

Figure 7 Average percentage changes in serum total cholesterol, triglycerides and potassium in reported studies using combinations of a potassium-loosing diuretic (almost always thiazides) with a potassium-sparing diuretic.

Mean $\pm S D$. There were no significant differences between combinations including either spironolactone, triamterene or amiloride.

Since effects of thiazides on serum potassium, glucose and uric acid are dose-dependent, in low doses they may be also less prone to modify the lipoprotein profile ${ }^{[60]}$. Nevertheless, similar increases in serum total cholesterol and LDL-C were noted in hypertensive men receiving during up to 42 months either $<50$ or $>50 \mathrm{mg}$ hydrochlorothiazide daily ${ }^{[27]}$, in nine subjects treated during $\geq 6$ months with hydrochlorothiazide, $50 \mathrm{mg}$. day ${ }^{-1}$, and then during 6 months $25 \mathrm{mg}$. day ${ }^{-1[6] !}$, or in nine postmenopausal women receiving during subsequent 1 month periods 12.5 as compared with $112.5 \mathrm{mg}$ hydrochlorothiazide daily ${ }^{[62]}$. On the other hand, measurements in patients with mild hypertension (average age 55 years, $38 \%$ women) after 1 year of therapy with nutritionalhygienic intervention combined with different types of antihypertensive drugs revealed that low dose chlorthalidone $\left(15 \mathrm{mg}\right.$. day $\left.{ }^{-1}\right)$ was associated with minimal increases in total cholesterol $(+0.5 \%)$ and LDL-C $(+1 \%)$, whereas administration of placebo or drugs thought to be neutral with regard to total and LDL-C (amlodipine, enalapril) were accompanied by mild decreases in total cholesterol $(-2$ to $-3 \%)$ and LDL-C $(-1$ to $-3 \%)$ (Fig. 8). Nevertheless, changes in HDL-C/ total cholesterol ratio did not differ significantly between low-dose chlorthalidone $(+5 \%)$ and the other treatments $(+8$ to $+10 \%)(\text { Fig. } 9)^{(63)]}$.

\section{Possible mechanisms}

The mechanisms of diuretic-induced dyslipidaemia are still unclear. Nevertheless, diuretics, particularly when administered in high dosage, can slightly increase sympathetic nervous activity ${ }^{[64]}$ and/or levels of circulating norepinephrine. This may, in turn, promote lipolysis ${ }^{(65)}$, stimulate the hepatic synthesis of cholesterol subsequently secreted as VLDL and probably also raise the 

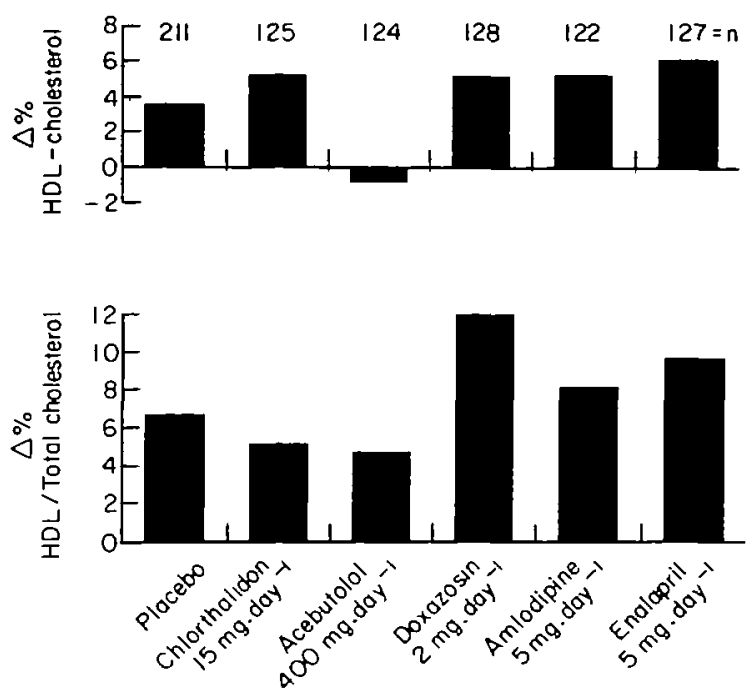

Figure 9 Percentage changes in serum HDL cholesterol or the HDL/total cholesterol ratio after 1 year of therapy with different types of agents in the treatment of muld hypertension study. (Data based on $\left.{ }^{(-3)}\right)$.

atherogenic serum cholesterol fraction. Dependence of the latter on noradrenergic modulation is suggested by a positive correlation between plasma norepinephrine and LDL+ VLDL-C both before and after sympathetic neurone blockade in patients with essential hypertension or renal failure ${ }^{[6]}$. Thiazide-type and loop diuretics can also impair insulin sensitivity ${ }^{[67]}$. Changes in potassium may possibly play a role in this interaction ${ }^{[33]}$. The latter and/or the resulting compensatory hyperinsulinaemia are known to promote hypertriglyceridaemia, a tendency for low HDL-C, and atherogenesis ${ }^{[68]}$. It can be hypothesized that, with intact lipoprotein lipase activity, excess VLDL could be metabolized to LDL-C, thereby contributing perhaps also to increased total serum cholesterol concentration.

\section{Other antihypertensive agents}

Several $\beta$-blockers tend to increase $\mathrm{Tg}$ and decrease HDL-C. These changes are most prominent on unselective $\beta_{1+2}$-blockers without intrinsic sympathomimetic activity (ISA), less pronounced on selective $\beta_{1}$-blockers without ISA, discrete on $\beta$-blockers with modest ISA and largely absent on $\beta$-blockers with pronounced ISA ${ }^{[9,12]}$. Some $\beta$-blockers can also slightly reduce insulin sensitivity and/or secretion and during long-term treatment impair glucose tolerance, particularly when they are administered in combination with diuretics ${ }^{[30]}$. Celiprolol, a $\beta_{1}$ blocker with concomitant $\beta_{2}$-agonism and $a_{2}$-antagonism, tends to decrease $\mathrm{Tg}$ and increase HDL- $\mathrm{C}^{(30)}$.

Considering combination treatment, diuretic-induced increases in LDL-C may, at least in the short-term, be prevented by the concomitant administration of certain $\beta$-blockers ${ }^{(69.70)}$.

Postsynaptic $a_{\mathrm{f}}$-blockers can slightly decrease $\mathrm{Tg}$, LDL-C and the total C/HDL-C ratio, while insulin sensitivity, insulin secretion and glucose tolerance may tend to be improved ${ }^{[12.30]}$. Some other sympatholytics are largely neutral with regard to lipoproteins and glucose tolerance.

ACE inhibitors, calcium channel blockers and the serotonin ${ }_{2}$-receptor blocker ketanserin do not adversely affect serum lipoproteins ${ }^{[12.30 .71]}$. ACE inhibitors tend to decrease serum total $\mathrm{Tg}$ and slightly improve insulin sensitivity and glucose tolerance ${ }^{[30]}$. The latter has been largely unchanged in clinical studies of calcium channel blockers or ketanserin; nevertheless, whether or not clinical treatment with such agents can produce subtle changes in insulin sensitivity or secretion is presently unclear.

\section{Relevance and outlook}

Whether the lipoprotein changes induced by certain antihypertensive drugs can per se modify the long-term prognosis of patients so treated is still unclear. In patients with high serum cholesterol concentration (pre-treatment C $>6.5 \mathrm{~mm} \mathrm{.} 1^{-1}$ ), long-term C-lowering with either diet or drugs produced a $1.5 \%$ decrease in coronary heart disease for every $1 \%$ reduction in serum cholesterol. Whether this correlation also holds for both decreases and increases from initially normal or mildly elevated serum cholesterol levels is not yet known. Therefore, attempts to calculate a potential impact of diuretic-induced increases in serum total cholesterol and LDL-C on coronary prognosis would be speculative.

Whatever the relative contribution of dyslipidaemia, diuretic therapy may concomitantly aggravate several potential cardiac risk factors, including impaired insulin sensitivity with compensatory hyperinsulinaemia, electrolyte imbalance, sympathetic and angiotensin IIstimulation, and others. Although it has been difficult to demonstrate a primary preventive effect of $\beta$-blockers on coronary prognosis, such agents, and particularly those without ISA, have been found to be effective at least in the secondary prevention of myocardial infarction. Therefore, $\beta$-blockers may possibly have a beneficial effect on some key steps involved in atheroma formation ${ }^{[72,73]}$. It follows that diuretics and $\beta$-blockers have done at least 'some good', while a prognostic efficacy of newer drug classes, such as calcium channel blockers, ACE-inhibitors, postsynaptic $a-1$ blockers and $S_{2}$-blockers remains to be demonstrated.

Finally, it is important to note that observations on interactions of antihypertensive agents with lipoproteins have so far been limited largely to serum concentrations. However, lipid binding to vascular cells, the uptake, concentrations and metabolic processes in vascular cells rather than in the blood stream are decisive for atherogenesis, and effects of the different antihypertensive agents at the cellular level remain to be investigated. Therefore, possible differential indications for the various antihypertensive drugs are only beginning to emerge. Still, at this stage, it is of clinical interest that several of the generally available antihypertensive drugs seem to be metabolically 'neutral' or sometimes perhaps even potentially beneficial with regard to the lipoprotein and glucose metabolism. 


\section{References}

[1] Helgeland A. Treatment of mild hypertension: a five year controlled drug trial. Am J Med 1980; 69: 725-32.

[2] Morgan TO, Adams WR, Hodgson M, Gibberd RW. Failure of therapy to improve prognosis in elderly males with hypertension. Med J Australia 1980; 2: 27-31.

[3] Multiple Risk Factor Intervention Trial. Risk factor changes and mortality results. JAMA 1982; 248: 1465-77.

[4] Collins R, Peto R, MacMahon S et al. Blood pressure, stroke and coronary heart disease. Part 2, short-term reductions in blood pressure: overview of randomized drug trials in their epidemiological context. Lancet 1990; i: 827-38.

[5] Medical Research Council Working Party. MRC trial of treatment of mild hypertension: principal results. Br Med J 1985; 29l: $97-104$

[6] Castelli WP. Epidemiology of coronary heart disease: the Framingham study. Am J Med 1984; 76 (Suppl 2A): 4-12

[7] Carlson LA, Roessner S. Risk factors for myocardial infarction in the Stockholm Prospective Study. Acta Med Scand 1979; 206: 351-60.

[8] Assmann G, Schulte H. The Prospective Cardiovascular Munster (PROCAM) study: prevalence of hyperlipidemia in persons with hypertension and/or diabetes mellitus and the relationship to coronary heart disease. Am Heart J 1988; 116 (Suppl 2): 1713-24.

[9] Weidmann P, Gerber A, Mordasini R Effects of antihypertensive therapy on serum lipoproteins. Hypertension 1983; (Suppl III): 120-31

[10] Weidmann P, Uehlinger DE, Gerber A. Antihypertensive treatment and serum lipoproteins. J Hypertens 1985; 3: 297-306.

[11] Ames RP. Effects of diuretic drugs on the lipid profile. Drugs 1988; 36 (Suppl 2): 33-40.

[12] Weidmann P, Ferrier C, Saxenhofer H, Uehlinger DE, Trost BN. Serum lipoproteins during treatment with antihypertensive drugs. Drugs 1988; 35 (Suppl 6): 118-34.

[13] Safar M, Simon A, Ben Maiz H, Weiss Y, Milliez P. Hypertensions arterielles severes traitees medicalement. Evolution a long terme. Nouvelle Presse Med 1975; 4: 1403-6.

[14] Glueck Z, Baumgartner G, Weldmann P et al. Increased ratio between beta- and alpha-lipoproteins during diuretic therapy: an adverse effect? Clin Sci Mol Med 1978; 55: 325S-8S.

[15] Van Brummelen P, Gevers Leuven JA, Van Gent CM. Influence of hydrochlorothiazide on the plasma levels of triglycerides, total cholesterol and HDL cholesterol in patients with essential hypertension. Curr Med Res Opin 1979; 6: 24-29.

[16] Glueck Z, Weidmann P, Mordasini R et al. Increased serum low-density lipoprotein cholesterol in men treated short-term with the diuretic chlortalidone. Metabolism 1980; 29: 240-5.

[17] Rosenthal T, Holtzmann E, Segal P. The effects of chlortalidone on serum lipids and lipoproteins. Atherosclerosis 1980; 36: 111-5.

[18] Grimm RH, Leon AS, Hunninghake DB, Lenz K, Hannan P, Blackburn $H$. Effects of thiazide diuretics on plasma lipids and lipoproteins in mildly hypertensive patients. Ann Int Med 1981; 94: 7- 11.

[19] Meier A, Schiff H, Weidmann P, Mordasini R, Riesen W, Bachmann $C$. Beta receptor blocking agents may reverse or prevent diuretic-induced increases in serum low-density lipoprotein cholesterol. Clin Sci 1981; 61: 437S-9S.

[20] Hubbell FA, Weber MA, Winer RL, Rose DE. Biochemical cardiac risk factors during diurctic therapy. Arch Int Pharmacodyn 1982; 256: 123-33.

[21] Veterans Administration Cooperative Study Group on Antihypertensive Agents. Comparison of propranolol and hydrochlorothiazide for the initial treatment of hypertension. JAMA 1982; 248: 1995-2011.

[22] Johnson BF, Romero L, Johnson J, Marwaha R. Comparative effects of propranolol and prazosin upon serum lipids in thiazide-treated hypertensive patients. Am J Med 1984; 76 (2A): $109-12$.
[23] Lasser NL, Grandits G, Caggiula AW et al. Effects of antihypertensive therapy on plasma lipids and lipoproteins in the MRFIT. Am J Med 1984; 76 (2A): 52-66.

[24] Weinberger MH. Blood pressure and metabolic responses to hydrochlorothiazide, captopril and the combination in black and white mild-to moderate hypertensive patients. J Cardiovase Pharm 1985; 7: S52-5.

[25] Johnson BF, Weiner B, Marwaha R, Johnson J. The influence of pindolol and HCT on blood pressure and plasma renin and plasma lipid levels. J Clin Pharmacol 1986; 26: 258-63.

[26] Williams WR, Schneider KA, Borhani NO, Schnaper HW, Slotkoff LM, Ellefson RD. The relationship between diuretics and serum cholesterol in Hypertension Detection and Follow-up Program participants. Am J Prev Med 1986; 2 : 248-55.

[27] Middeke M, Weiswetler P, Schwandt P. Serum lipoproteins during antihypertensive therapy with beta blockers and diuretics; $A$ controlled long-term comparative trial. Clin Cardiol 1987; 10: 94-8.

[28] Williams LL, Lopez LM, Thorman AD, Quay GP, Steın GH, Mehta JL. Plasma lipid profiles and antihypertensive agents; effects on lisinopril, enalapril, nitrendipine, hydralazine and hydrochlorothiazide. Drug Intell Clin Pharm 1988; 22 $546-50$.

[29] Stamler R, Stamler J, Gosch FC, Berkson DM, Dyer AR, Hershinow $P$. Initial anthhypertensive drug therapy-a comparison of alpha-blocker (prazosin) and diuretic (hydrochlorothiazide). Am J Med 1989; 86 (1B): 24-5.

[30] Ferrari P, Rosman J, Weidmann P. Antihypertensive agents, serum lipoproteins and glucose metabolism. Am J Cardiol 1991; 67: 26B-35B

[3I] Holzgreve H, Middeke M. Concomitant considerations in longterm antihypertensive treatment. J Hum Hypertens 1990; 4 (Suppl 5): 11-8.

[32] Boehringer K, Weidmann P, Mordasini R, Schiff H, Bachmann C, Riesen W. Menopause-dependent plasma lipoprotein alterations in diuretic-treated women. Annals Int Med 1982; 97: 206-9.

[33] Kovanen PT, Brown MS, Goldstein JL. Increased binding of low density lipoprotein to liver membranes from rats treated with 17-alpha-ethinyl estradiol. J Biol Chem 1979; 254: 1367-73.

[34] Ames RP, Hill P. Antihypertensive therapy and the risk of coronary heart disease. J Cardiovasc Pharmacol 19824 (Suppl 2): S206-12.

[35] Berglund G, Andersson O. Hydrochlorothiazide and spironolactone alone and in a fixed combination in hypertension. Curr Therap Res 1980;27:360-4.

[36] Falch DK, Schreiner A. The effect of spironolactone on lipid, glucose and uric acid levels in blood during long-term administration to hypertensives. Acta Med Scand 1983; 213: 27-30.

[37] Puig JG, Miranda ME, Mateos F, Herrero E, Lavilla P, Gil A Hydrochlorothiazide versus spironolactone: long-term metabolic modifications in patients with essential hypertension. J Clin Pharmacol 1991; 31: 455 61.

[38] Henry M, Wehrlen M, Pelletier B, Capron MH. Spironolactone versus nifedipine in essential hypertension. Am J Cardiol 1990; 65: $36 \mathrm{~K}-8 \mathrm{~K}$.

[39] Jeunemaître X, Châtellier G, Kreft-Jais C, Charru A, Devries $C$, Plouin PF, Corvol P, Ménard J. Efficacy and tolerance of spironolactone in essential hypertension. Am J Cardiol 1987; 60: 820-5.

[40] Plouin PF, Battaglia C, Alhenc-Gélas F, Corvol P. Are angiotensin converting enzyme inhibition and aldosterone antagonism equivalent in hypertensive patients over fifty? Am J Hypertens 1991; 4: 356-62.

[41] Scherstén B, Thulin T, Kuylenstierna J et al. Clinical and Biochemical effects of spironolactone administered once daily in primary hypertension. Hypertension 1980; 2: 672-9.

[42] Wild RA, Demers LM, Applebaum-Bowden D, Lenker R. Hirsutism: metabolic effects of two commoniy used oral 
contraceptives and spironolactone. Contraception 1991; 44: 113-24.

[43] Chrysant SG, Luu TM. Effects of amiloride on arterial pressure and renal function. J Clin Pharmacol 1980; 332-7.

[44] Alcazar JM, Rodicio JL, Ruilope LM. Long-term diuretic therapy and renal function in essential arterial hypertension. Am J Cardiol 1990; 65: $51 \mathrm{H}-4 \mathrm{H}$.

[45] Andersen B, Snortason S P, Ragnarsson J, Hardarson T. Hydrochlorothiazide and potassium chloride in comparison with hydrochlorothiazide and amiloride in the treatment of mild hypertension. Acta Med Scand 1985; 218: 449-54.

[46] Andrejak M, Santoni JP, Carré A et al. A double-blind comparison of perindopril and hydrochlorothiazide-amilonde in mild to moderate essential hypertension. Fundam Clin Pharmacol 1991; 5: 185-92.

[47] Birbar AE, Daouk MM, Mukaddam-Daher S. Efficacy and safety of lasilactone, a new combination diuretic, in essential hypertension. Gen Pharmac 1987; 18: 609-11.

[48] Boehringer K, Meier A, Weidmann P, Schiff H, Mordasini R, Riesen W. Einfluss von Hydrochlorothiazid/Amilorid allein oder in Kombination mit $a$-Methyldopa auf die Serumlipoproteine. Schweiz med Wschr 1981; 111: 525-30.

[49] Casner PR, Dillon KR. A comparison of the anti-hypertensive effectiveness of two triameterene/hydrochlorothiazide combinations: maxzide versus dyazide. J Clin Pharmacol 1990; 30: 715-9.

[50] Ferrara LA, Strazzullo P, Scillitani A, Mancini M, Gagliardi R. Cross-over study of muzolimine and hydrochlorothiazideamiloride in hypertensive patients. Eur J Clin Pharmacol 1985; 28: 241-4.

[51] Fritschka E, Schmidt G. Langzeitwirksamkeit und Nebenwirkungsprofil einer niedrigdosierten Bemetizid-TriamterenKombination bei Patienten mit essentieller Hypertonie. Med Klin 1989; 84: 526-33.

[52] Grünfeld JP, Wehrlen M, Pelletier B, Capron MH. Spironolactone and altizide versus converting enzyme inhibitor (enalapril). Am J Cardiol 1990; 65: 28K-32K.

[53] Jeunemaitre $X$, Charru A, Chatellier G et al. Long-term metabolic effects of spironolactone and thiazides combinated with potassium-sparing agents for treatment of essential hypertension. Am J Cardiol 1988; 62: 1072-7.

[54] Kirsten R, Kirch W, Heintz B. Trichlormethiazid-AmiloridKombination bei essentieller Hypertonie. Dtsch med Wschr 1985; 110: 37I-6

[55] Kohvakka A, Salo H, Gordin A. Antihypertensive and biochemical effects of different doses of hydrochlorothiazide alone or in combination with triamterene. Acta Med Scand 1986; 219 : $381-6$.

[56] Schiffl H, Schollmeyer P. Metabolic consequences of longterm thiazide-based antihypertensive treatment of renal hypertension. Cardiology 1985 (72 (Suppl 1): 54-6.

[57] Staessen J, Amery A, Birkenhäger $W$ et al. Is a high serum cholesterol level associated with longer survival in elderly hypertensives? J Hypertens 1990; 8: 755-61.
[58] Verhiest $\mathbf{W}$, Baehre $\mathbf{M}$, Volkers P. Companson of two combined diuretics in the treatment of essential hypertension. Int J Clin Pharm Ther Tox 1989; 342-5.

[59] Ferrari P, Weidmann P. Lipoproteins during antihypertensive therapy; focus on indapamide. South African Med J 1989; 7 (Suppl): 13-7.

[60] Carlsen JE, Kober L, Torp-Pedersen C, Johansen P. Relation between dose of bendrofluazide, antihypertensive effect, and adverse biochemical effects. Br Med J 1990; 300: 975-8.

[61] Kochar MS, Landry KM, Ristow SM. Effects of reduction in dose and discontinuation of hydrochlorothiazide in patients with controlled essential hypertension. Arch Intern Med 1990; 150: 1009-11

[62] McKenney JM, Goodman RP, Wright JT. The effect of lowdose hydrochlorothiazide on blood pressure, serum potassium, and lipoproteins. Pharmacotherapy $1986 ; 6$ : 179-84.

[63] The Treatment of Mild Hypertension Research Group. The treatment of mild hypertension study. A randomized, placebocontrolled trial of a nutritional-hygienic regimen along with various drug monotherapies. Arch Intern Med 1991; 151: 1413-23.

[64] Weidmann P, Beretta-Piccoli C, Meier A, Keusch G, Glück Z, Ziegler WH. Antihypertensive mechanism of diuretic treatment with chlorthalidone. Complementary roles of sympathetic axis and sodium. Kidney Int 1983; 23: 320-6.

[65] Keller U, Weiss M, Stauffacher W. Contribution of $a$ - and $\beta$ receptors to ketogenic and lipolytic effects of norepinephrine in humans. Diabetes 1989; 38: 454-9.

[66] Weidmann P, Schohn DC, Riesen W, Jahn HA, Ferrari P, Beretta-Piccoli C. Association between sympathetic activity and the atherogenic serum cholesterol fraction. Klin Wochenschr 1990; 68: 269-76.

[67] Pollare T, Lithell $\mathrm{H}$, Berne $\mathrm{C}$. Insulin resistance is a characteristic feature of primary hypertension independent of obesity. Metabolism 1990; 39: 167-74.

[68] Ferrari P, Weidmann P. Insulin, insulin sensitıvity and hypertension. J Hypertens 1990; 8: 49I-500.

[69] Meier A, Weidmann P, Mordasini R, Riesen W, Bachmann C. Reversal or prevention of diuretic induced alterations in serum lipoproteins with beta-blockers. Atherosclerosis 1982; 41: 415-9.

[70] Schiff H, Weidmann P, Mordasini R, Riesen W, Bachmann C. Reversal of diuretic-induced increases in serum low-density lipoprotein cholesterol by the betablocker pindolol. Metabolism 1982; 31: 411-5.

[71] Weidmann P, Ferrari P, Rosman J, de Courten M. Current antihypertensive drugs and serum lipoproteins. Royal Soc Med, Int Congress Symp Series 1992; 191: 35-56.

[72] Kaplan JR, Manuck SB, Adams MR, Weingand KW, Clarkson TB. Inhibition of coronary atherosclerosis by propranolol in behaviorally predisposed monkeys fed an atherogenic diet Circulation 1987; 76: 1364-72.

[73] Strawn WB, Bondjers G, Kaplan JR, Manuck SB, Schwenke DC, Hansson GK, Shively CA, Clarkson TB. Endothelial dysfunction in response to psychosocial stress in monkeys. Circ Res 1991; 68: 1270-9. 